\title{
Protecting Human Research Participants, IRBs, and Political Science Redux: Editor's Introduction
}

In the 1990s I testified before a National Science Foundation (NSF) panel headed by Cora Marrett, then assistant director for the NSF Directorate for the Social, Behavioral and Economic Sciences. The subject of the panel's inquiry, and this issue's symposium, was social science research and the federally mandated but decentralized human subjects protection program and its principal actors, institutional review boards (IRBs). My testimony addressed the ways in which the regulatory system ill-fit and ill-served political science research. IRBs had expanded their mission to include all research, not just research funded by the federal government, enhancing their scope of authority while slowing the timeliness of reviews. Similarly, and with the same result, IRBs were evaluating secondary research as well as primary research. Although the federal legislation provided for a nuanced assessment of risk, the distinction between potentially risk-laden research necessitating a full IRB review and research posing minimal or no risk that could be

either exempted or given expedited review was disappearing. The length of the review process threatened the beginning or completion of course work and degree programs. IRBs were judging the merits of research projects rather than the risks involved. This trend was especially problematic because representation on many IRBs was skewed toward biological and behavioral scientists often unfamiliar with the methods and fields of political science and the other social sciences. And the list went on.

In the years that followed there have been several efforts to reform human subject regulation. Oral historians waged a successful campaign to restore their exemption from IRB review. The University of Illinois's Center for Advanced Study wrote a white paper entitled "Improving the System for Protecting Human Subjects: Counteracting IRB 'Mission Creep'" (Gunsalus et al. 2007). The National Human Research Protection Advisory Committee, the National Research Panel on Institutional Review Boards, Surveys and Social Science Research sought to exempt secondary data analysis research from IRB review (Levine and Skeds- vold 2008, 503). In 2006, the National Conference on Alternative IRB Models was held. In the face of these and other efforts, are IRBs better able to effectively and efficiently protect human subjects in social science research?

Judging from the comments of the symposium authors, the answer is no. Now as in the past, IRBs have no consistently applied metric for measuring risk and corresponding levels of IRB review. Mitchell Seligson, Felice Levine and Paula Skedsvold, and Dvora Yanow and Peregrine Schwartz-Shea confirm that the review process has not and perhaps cannot accommodate survey methods and ethnographic and field research. The pace of the IRB review process continues to hinder undergraduate and graduate empirical research. IRBs' rigid interpretations of requirements produce logically inconsistent directives such as when researchers are told to destroy data they diligently collected and anticipated sharing in order to protect research subjects' anonymity (Seligson 2008; Yanow and Schwartz-Shea 2008; and Levine and Skedsvold 2008). According to Seligson the failures and weaknesses of the IRB system are the unintended consequences of public policy. Tony Porter's examination of research ethics governance in Canada shows that the challenges of devising an effective and efficient human subjects protection program are not limited to the United States. And one wonders what will happen in Canada and elsewhere if the flawed American system is diffused.

This symposium offers what might be done when the policy window on human protection program reform opens next. Seligson identifies the need to redefine research subject to regulation as all studies that obtain data on human subjects; that exemptions contained in the legislation should be enforced; faculty should become aware of IRB regulations; campus-based IRBs should provide exemptions to survey researchers who have demonstrated their understanding of the protection program's principles; and those who administer and serve on the campus IRBs should be retrained. Yanow and Schwartz-Shea go to the root of the fundamental incompatibility of the experimentally based regulatory system and field research design and methodologies. Levine and Skedsvold offer four ways for change: decentralizing the IRBs by providing for departmental or research unit 
review committees that would be familiar with research methods and better able to assess risk; simplifying and facilitating expedited reviews through departmental and research unit committees; enforcing the exemption for public use data files that have been vetted through an IRB the original producer or provider; and shifting the focus of IRBs from compliance to educating investigators in better ways to satisfy the human protection guidelines.

It is easy to assume that there is a fundamental incompatibility between human protection regulation and political science. Reforming the IRB system would better serve political science, but Sue Tolleson-Rinehart expands our discussion by identifying the many ways in which political science research could be used to improve the regulatory system itself as well as the "quality, safety, and effectiveness of our health care system" (2008, 507).

Knowing what to do and having the will to do it are not the same. The symposium authors offer a rich set of reforms. Reform has yet to gain traction despite repeated efforts over the past decade or so to accommodate human protection regulation and social science research. When will it happen? I have said in the past that the push to reform is one incident of blatant subject abuse and/or a change in the federal administration away.
In all likelihood the abuse will involve biomedical research and reform efforts will consider the needs of the social sciences (and humanities) tangentially. But perhaps not; Levine and Skedsvold believe the time to work for change is at hand given more than a decade's work on identifying problems and solutions and the empirical research to support system reform.

How will the social sciences get the attention of regulators? Yanow and Schwartz-Shea outline a number of initiatives that APSA and other social science organizations can adopt to hurry change along, including monitoring IRB policy, gathering information on the regulatory problems facing political scientists, advocating on behalf of reform, and promoting wider discussion of IRB policy in political science and the other social sciences, to name a few. APSA has and will continue to monitor and advocate on behalf of the proper place of social sciences in IRB policy. This symposium is itself an effort to educate member as to the challenges and potential solutions. Most recently, APSA and other scholarly societies made specific recommendations to the Department of Health and Human Services's Office for Human Research Protections on proposed revisions to the expedited categories of research. The efforts will continue and hopefully will succeed in bringing about meaningful change sooner rather than later.

\section{References}

Gunsalus, C. Kristina, Edward Bruner, Nicholas Burbules, Leon DeCosta Dash Jr., Matthew W. Finkin, Joseph Goldberg, William Greenough, Gregory Miller, and Michael G. Pratt. 2007. "The Illinois White Paper: Improving the System for Protecting Human Subjects; Counteracting IRB Mission Creep." Qualitative Inquiry 13 (5): 617-49.

Levine, Felice J., and Paula R. Skedsvold. 2008. "Where the Rubber Meets the Road: Aligning IRBs and Research Practice." PS: Political Science and Politics 41 (July): 501-05.

Porter, Tony. 2008. "Research Ethics Governance and Political Science in Canada." PS: Political Science and Politics 41 (July): 495-99.
Seligson, Mitchell A. 2008. "Human Subjects Protection and Large-N Research: When Exempt is Non-Exempt and Research is Non-Research." PS: Political Science and Politics 41 (July): 477-82.

Tolleson-Rinehart, Sue. 2008. "A Collision of Noble Goals: Protecting Human Subjects, Improving Health Care, and a Research Agenda for Political Science.” PS: Political Science and Politics 41 (July): 507-11. Yanow, Dvora, and Peregrine Schwartz-Shea. 2008. "Reforming Institutional Review Board Policy: Issues in Implementation and Field Research." PS: Political Science and Politics 41 (July): 483-94.

America: Political Support and Democracy in Eight Nations (Cambridge University Press, forthcoming).

Paula Skedsvold is director of Education Research Policy for the American Educational Research Association. She is trained in both experimental social psychology and law, and has spent most of her career in policy settings. She previously staffed the Social and Behavioral Sciences Working Group of the National Human Research Protections Advisory Committee. She may be contacted at: pskedsvold@aera.net.

Sue Tolleson-Rinehart is assistant chair for Faculty Development, Department of Pediatrics, and co-associate director of the MD-MPH Program, in the Schools of Medicine and Public Health. Her e-mail address is suetr@unc.edu.

Dvora Yanow holds the strategic chair in Meaning and Method at the Vrije Universiteit (Amsterdam). Her research has been shaped by an overall interest in the communication of meaning in organizational and policy settings. Her most recent empirical research, Constructing American "Race" and "Ethnicity": Category-Making in Public Policy and Administration (M E Sharpe, 2003), was awarded the 2004 ASPA and 2007 Herbert A. Simon-APSA book prizes. Together with Peregrine Schwartz-Shea, she co-edited Interpretation and Method: Empirical Research Methods and the "Interpretive Turn" (M E Sharpe, 2006). She can be reached at: d.yanow@fsw.vu.nl. 